\title{
E-transparência: proposta de modelo metodológico para avaliação de portais de executivos nacionais
}

\section{E-transparency: proposal a methodological model to the analysis of transparency in national executives portals}

\author{
Paula Karini Amorim | Instituto Federal de Educação do Tocantins \\ Professora do curso de Gestão Pública do Instituto Federal do Tocantins \\ Doutora em Comunicação e Cultura Contemporêneas pela UFBA \\ Pesquisadora associada do CEADD \\ E-mail: paulakarini@ifto.edu.br
}

Maria Paula Almada | Universidade Federal da Bahia Doutoranda em Comunicação e Cultura Contemporâneas (Facom/UFBA) e pesquisadora do Centro de Estudos Avançados em Democracia Digital e Governo Eletrônico (CEADD-UFBA).

E-mail: mariapaula.almada@gmail.com

\begin{abstract}
Resumo
Este trabalho propôe um modelo metodológico para a análise da transparência em portais de executivos nacionais. Tal metodologia visa avaliar os modos pelos quais governos nacionais empregam a internet para oferecer informação e serviços que visam incrementar a transparência da gestão pública. Propõe-se uma metodologia em quatro etapas: (1) identificação dos experimentos; (2) estudo exploratório; (3) navegação estruturada, e; (4) análise comparativa dos resultados por meio da estatística descritiva regressão multivariada. A última etapa visa verificar a existência de associação do índice de transparência com indicadores sociais (IDH e inserção digital), políticos (tipo de regime) e econômicos (PIB) dos países estudados. Por fim, testa-se o modelo proposto no portal do Poder Executivo brasileiro.
\end{abstract}

Palavras-Chave: democracia digital; governo eletrônico; e-transparência.

\begin{abstract}
This study, in the sphere of e-government and digital democracy, proposes a methodological model to the analysis of transparency in national executives' portals. Such methodology aims to evaluate ways and means by which national governments, through its online portals, use the Internet to provide information and services in order to promote visibility and increase transparency of public management. It is proposed a methodology in four steps: (1) identification of the experiments; (2) exploratory study; (3) structured navigation in portals, and; (4) Comparative analysis of the results using descriptive statistics and multivariate regression analysis. This last step aims to verify the existence of association of the transparency index with social indicators (HDI and digital insertion), political (regime type) and economic (GDP) of the countries being studied. Finally, we test the methodological model proposed in the portal of the Brazilian Executive Branch.
\end{abstract}

Keywords: e-democracy; e-government; e-transparency. 


\section{Transparência na Administração Pública}

A transparência pública é considerada um requisito básico da democracia representativa contemporânea. Trata-se do ato de jogar luz sobre processos internos decisórios cujos resultados atingem, de algum modo, o cidadão.

A definição de transparência perpassa a visibilidade de dados e informações técnicas, contábeis, estatísticas e econômicas sobre representantes e negócios públicos preocupando-se, sobretudo, com a inteligibilidade desses dados (HEALD, 2006). Por assumir a forma mais desejada de visibilidade pública, a reivindicação por transparência em informaçóes governamentais, discursos políticos e inclusive na cobertura jornalística se tornou comum hoje, sendo frequentemente citada em estudos e análises (MARGETTS, 2006, HEALD, 2006).

Este conceito tem sido mencionado desde os primeiros debates sobre a informatização, como um dos conceitos chave da tecnologia da informação desde os anos 1980 (HEALD, 2006). Aspectos que vão desde a quantidade de informação disponível até a qualidade destas, passando por questóes como acessibilidade, inteligibilidade e possibilidades de constrangimento aos representantes, caracterizam a transparência como um requisito democrático que pressupóe robustez de informação, acessibilidade assincrônica e inexistência de barreiras cognitivas ao cidadão comum (SILVA, 2009). A transparência, então, emerge como um valor necessário para o Estado se tornar mais visível e mais próximo do cidadão por meio da oferta de informaçóes e serviços que possam favorecer a comunicação, o controle, a deliberação e a participação civil.

Com advento das tecnologias digitais de comunicação e informação, muitos pesquisadores têm se debruçado, desde os anos 1990, sobre as reais possibilidades da internet para o aprimoramento de requisitos democráticos básicos, que vão desde o provimento de informação clara e de qualidade que munam o cidadão de know how não apenas para escolher bem seus representantes em tempos de eleição, como também para acompanhá-los, monitorá-los e vigiá-los, até a possibilidade de influência efetiva do cidadão na tomada de decisóes políticas.

Neste contexto, a ideia de transparência e sua aplicabilidade aos órgãos e instituiçôes públicas têm adquirido, desde as duas últimas décadas do século passado, cada vez mais força em todo o mundo (HOOD, 2006). Pode-se dizer que hoje é tão importante quanto necessário que portais governamentais ofereçam informações de qualidade aos seus cidadãos possibilitando que estes acompanhem, monitorem e participem das atividades e tomadas de decisão da esfera política.

Diversas instituiçóes e órgáos governamentais e da sociedade civil têm se dedicado a avaliar como governos e instituiçôes públicas disponibilizam seus dados aos cidadãos, e a criar acordos e parcerias para promover e aprimorar a transparência dos dados públicos oferecidos por governos em diversos países. É o caso do International Budget Partnership (IBP), que desde 2006 avalia bianualmente as práticas orçamentárias de diversos países através da análise da qualidade dos orçamentos e das informaçóes dispostas online, e do Open Government Partnership (OGP), lançado em setembro de 2011, que reúne governos e sociedade civil no intuito de promover a transparência, lutar contra a corrupção e usar novas tecnologias para reforçar a governança. 
No Brasil, algumas medidas legais têm sido adotadas para garantir a obrigatoriedade da prestação de contas de agentes do Estado e, assim, possibilitar o monitoramento do cidadão às contas e gastos públicos. Em maio de 2012, entrou em vigor a Lei Federal n 12.527/2011, mais conhecida como Lei de Acesso à Informação, que determina a obrigatoriedade de todo órgão ou entidade que recebe recursos públicos a divulgar onde os recursos estáo sendo aplicados, como estáo sendo aplicados e, inclusive, a motivação para que esse dinheiro seja alocado em determinado local e de determinada forma, reiterando, assim, a natureza pública das atividades desenvolvidas pelos órgáos de governo de todos os poderes em todas as esferas de governo.

No entanto, apesar de já haver considerável literatura sobre os aspectos normativos implicados na noção de transparência governamental (BRAGA, 2007, MARQUES 2014, SILVA, 2009), há pouquíssimo acúmulo de estudos de natureza empírica sobre as iniciativas estatais projetadas para a promoção da e-transparência (AMORIM, 2012, AMORIM e GOMES, 2013), seja no que tange à descrição de tais iniciativas quanto no que se refere à formulação e aplicação de indicadores para a avaliação dos graus e níveis de transparência alcançados nas experiências de transparência digital promovidas pelos governos.

Visando enfrentar esta lacuna na bibliografia, e no intuito de possibilitar uma análise das informaçóes dispostas em portais governamentais, este trabalho tem como proposta desenhar um modelo metodológico para a análise do estado da e-transparência em portais de executivos nacionais.

\section{Modelo metodológico para análise da transparência em executivos nacionais}

Para avaliar os meios e modos pelos quais governos nacionais empregam a internet para oferecer informação e serviços que visam promover a visibilidade e incrementar a transparência da gestão pública, propóe-se uma metodologia em quatro etapas, a saber:

Etapa 1 - caracterização dos experimentos por meio de pesquisa nas ferramentas de busca da Internet, visando catalogar os sites oficiais dos países a serem objeto de estudo pelo pesquisador;

Etapa 2 - estudo exploratório com a finalidade de compreender fenômenos e experiências que podem fundamentar e/ou testar as hipóteses, bem como auxiliar na elaboração e validação do conjunto de indicadores que irão compor o modelo de análise do estágio de desenvolvimento da transparência digital dos sites pesquisados;

Etapa 3 - coleta de dados e informações baseada na observação sistemática através de navegação orientada nos portais de executivos nacionais que se pretende analisar. Nesta etapa, o objetivo é acumular um conjunto de informaçóes, observaçôes e dados necessários à compreensão e análise do fenômeno estudado. Para tanto, propóe-se que sejam analisados todos os indicadores presentes na tabela 1.

Tabela 1 - Dimensóes, categorias de análise e indicadores da E-transparência. Fonte: adaptado 
de Amorim e Gomes (2013).

\begin{tabular}{|c|c|c|}
\hline Dimensão & Categorias de Análise & Indicadores \\
\hline \multirow{5}{*}{ I- Gerais } & \multirow{4}{*}{ Perfil do país } & IDH \\
\hline & & PIB \\
\hline & & Acesso à banda larga \\
\hline & & Tipo de Regime \\
\hline & Condiçōes Preliminares & Endereço Eletrônico do portal \\
\hline \multirow{11}{*}{$\begin{array}{l}\text { II - Eficácia } \\
\text { Digital }\end{array}$} & \multirow{9}{*}{$\begin{array}{l}\text { Usabilidade e } \\
\text { Acessibilidade }\end{array}$} & Existência de portal da transparência \\
\hline & & Visibilidade do portal da transparência \\
\hline & & Interface lógica \\
\hline & & Interface Gráfica \\
\hline & & Alternativa para plataformas móveis \\
\hline & & $\begin{array}{l}\text { Conformidade com normas de acesso à portadores de necessi- } \\
\text { dades especiais }\end{array}$ \\
\hline & & Alternativa para outros idiomas \\
\hline & & Flexibilidade e Eficiência do portal \\
\hline & & Instrumento para acompanhamento das atualizaçôes do site \\
\hline & \multirow{2}{*}{ Hiperlinks } & Link para Organismos de controle \\
\hline & & Link para outros sites e portais destinados a promover transparência \\
\hline \multirow{26}{*}{$\begin{array}{l}\text { III - Transparência } \\
\text { Digital }\end{array}$} & \multirow{8}{*}{$\begin{array}{l}\text { Habilitação do cidadáo } \\
\text { para compreensão da } \\
\text { informação }\end{array}$} & Educação para o controle social \\
\hline & & $\begin{array}{l}\text { Informaçóes que permitam ao cidadão identificar responsáveis } \\
\text { e autoridades e entrar em contato }\end{array}$ \\
\hline & & Conselhos Nacionais \\
\hline & & Ouvidoria \\
\hline & & Informaçōes sobre os meios de participaçáo \\
\hline & & Informaçóes sobre o funcionamento do governo \\
\hline & & Legislaçōes do governo \\
\hline & & Programas e projetos do governo \\
\hline & \multirow{6}{*}{$\begin{array}{l}\text { Informaçōes } \\
\text { financeiro-orçamentárias }\end{array}$} & Declaração Pré-orçamentária \\
\hline & & Proposta de orçamento do executivo \\
\hline & & Orçamento promulgado \\
\hline & & Relatórios de execução e de revisão \\
\hline & & Abertura de dados financeiro-orçamentário \\
\hline & & Orçamento do cidadáo \\
\hline & \multirow{4}{*}{$\begin{array}{l}\text { Informaçōes admi- } \\
\text { nistrativas (processos } \\
\text { internos) }\end{array}$} & Folha de pagamento (detalhamento atualizado) \\
\hline & & Licitaçôes \\
\hline & & Açôes e decisóes governamentais \\
\hline & & Abertura de dados da administraçấo \\
\hline & \multirow{8}{*}{$\begin{array}{l}\text { Instrumento de acom- } \\
\text { panhamento e interaçáo }\end{array}$} & Instrumento para acompanhamento das políticas públicas \\
\hline & & Agenda pública \\
\hline & & Avaliação dos serviços do governo \\
\hline & & Acompanhamento das demandas \\
\hline & & Respostas das autoridades e perguntas e respostas frequentes \\
\hline & & Atendimento online \\
\hline & & Debate prévio (plataformas deliberativas) \\
\hline & & Participaçáo em redes sociais \\
\hline
\end{tabular}


Cada indicador deve ser qualificado por conceitos. Os conceitos são aspectos avaliados por meio da atribuição de pontos, em função das suas características e peculiaridades para realizar a aferição. Os conceitos podem variar entre: localizado (4 pontos) ou não localizado ( 0 pontos); muito bom (4 pontos), regular (2 pontos), não existe (0 pontos); ou ainda muito bom (4 pontos), bom (3 pontos), regular ( 2 pontos), fraco (1 ponto) e não existe (0 pontos). Os conceitos parciais de cada indicador geram os conceitos das respectivas categorias.

Em face da necessidade de atribuir a devida relevância aos indicadores necessários para aferir o nível de transparência, foram definidos pesos: há aspectos muitos relevantes, que, por serem exigidos por lei recebem um peso maior (75\%). Há também aspectos de menor relevância (desejáveis), que são aqueles que, quando encontrados, facilitam ainda mais a obtenção da informação pelo cidadão: estes têm um peso menor (25\%).

Etapa 4 - análise comparativa dos casos por meio da técnica da estatística descritiva e da análise de regressão multivariada, visando verificar a existência de associação do índice de transparência com os indicadores sociais (IDH e inserção digital), políticos (tipo de regime) e econômicos (PIB) de cada país.

A seguir são descritas as dimensôes com os seus respectivos conceitos e critérios de avaliação.

\section{Eficácia digital}

A dimensão eficácia digital está subdividida em duas categorias a saber: (1) usabilidade e acessibilidade e (2) hiperlinks. Esta dimensão tem por finalidade verificar a organização e a arquitetura da informação, bem como a integração entre design, conteúdos e serviços do portal, além da capacidade de comunicação de forma transparente com outros sistemas.

Usabilidade e acessibilidade

Tabela 2 - Usabilidade e acessibilidade

\begin{tabular}{|l|l|c|}
\hline Indicadores & Conceitos & Pontuaçáo \\
\hline \multirow{5}{*}{ Portal da Transparência } & $\begin{array}{l}\text { Localizado - quando há link para o Portal da Transparência } \\
\text { dentro do site do governo. }\end{array}$ & 4 \\
\cline { 2 - 3 } & $\begin{array}{l}\text { Náo localizado - quando náo há link para o Portal da } \\
\text { Transparência dentro do site do governo. }\end{array}$ & 0 \\
\hline \multirow{5}{*}{$\begin{array}{l}\text { Visibilidade do Portal da } \\
\text { Transparência }\end{array}$} & $\begin{array}{l}\text { Muito bom - quando a localizaçáo do Portal da Transparência } \\
\text { no site do governo favorece a visibilidade e está localizado na } \\
\text { página principal. Ex.: banner próprio. }\end{array}$ & 4 \\
\cline { 2 - 3 } & $\begin{array}{l}\text { Bom - quando a localizaçáo do Portal da Transparência está } \\
\text { em menu na página principal. }\end{array}$ & $\begin{array}{l}\text { Regular - quando a localizaçáo do Portal da Transparência } \\
\text { no site do governo está em um menu secundário da página } \\
\text { principal. }\end{array}$ \\
\cline { 2 - 3 } & $\begin{array}{l}\text { Fraco - quando a localização do Portal da Transparência requer } \\
\text { o uso de mecanismo de busca no site do governo. }\end{array}$ & 2 \\
\cline { 2 - 3 } & $\begin{array}{l}\text { Não existe - quando náo há Portal da Transparência no site do } \\
\text { governo. }\end{array}$ & 0 \\
\hline
\end{tabular}




\begin{tabular}{|c|c|c|}
\hline Indicadores & Conceitos & Pontuação \\
\hline \multirow{5}{*}{ Interface lógica } & $\begin{array}{l}\text { Muito bom - (1) quando o portal fornece mecanismo de busca, } \\
\text { (2) mapa do site na página principal e (3) existem ferramentas } \\
\text { de busca avançada; (4) quando as páginas têm títulos de iden- } \\
\text { tificação tanto nas barras de janela como na área de conteúdos; } \\
\text { (5) a estrutura de organizaçáo hierárquica das informaçôes do } \\
\text { site favorece aprendizagem e memorizaçáo do usuário; (6) há } \\
\text { facilidade de navegar entre as diferentes seçóes do site a partir } \\
\text { de qualquer página; e (7) o site fornece identificação da institui- } \\
\text { çâa e (8) referências para contato em todas as páginas. }\end{array}$ & 4 \\
\hline & $\begin{array}{l}\text { Bom - quando o portal apresenta entre seis e sete dos itens } \\
\text { descritos acima. }\end{array}$ & 3 \\
\hline & $\begin{array}{l}\text { Regular - quando o portal apresenta entre quatro e cinco dos } \\
\text { itens descritos acima. }\end{array}$ & 2 \\
\hline & $\begin{array}{l}\text { Fraco - quando o portal apresenta entre dois e três dos itens } \\
\text { descritos acima. }\end{array}$ & 1 \\
\hline & $\begin{array}{l}\text { Não atende - quando o portal apresenta entre zero e um dos } \\
\text { itens descritos acima. }\end{array}$ & 0 \\
\hline \multirow{5}{*}{ Interface gráfica } & $\begin{array}{l}\text { Muito bom - (1) quando o aspecto visual do site é atraente e } \\
\text { adequado; (2) os elementos de informação estáo dispostos nas } \\
\text { páginas de forma organizada e racional; (3) há boa distinção } \\
\text { visual entre os diferentes elementos de interface, elementos de } \\
\text { navegação, elementos de conteúdo; (4) são usadas variaçōes de } \\
\text { hierarquia tipográfica para distinguir as diferentes partes do } \\
\text { texto, de forma clara e organizada (identifica titulo, subtítulo } \\
\text { e link). }\end{array}$ & 4 \\
\hline & Bom - quando o portal apresenta três dos itens descritos acima. & 3 \\
\hline & $\begin{array}{l}\text { Regular - quando o portal apresenta dois dos itens descritos } \\
\text { acima. }\end{array}$ & 2 \\
\hline & $\begin{array}{l}\text { Fraco - quando o portal apresenta pelo menos um dos itens } \\
\text { descritos acima. }\end{array}$ & 1 \\
\hline & $\begin{array}{l}\text { Não existe - quando os elementos da interface do portal não } \\
\text { favorecem uso e movimentaçáo do usuário }\end{array}$ & 0 \\
\hline \multirow{3}{*}{$\begin{array}{l}\text { Alternativa para plataformas } \\
\text { móveis }\end{array}$} & $\begin{array}{l}\text { Muito bom - quando o portal fornece meios de acesso para que } \\
\text { o usuário possa acessá-lo por meio de dispositivos móveis. }\end{array}$ & 4 \\
\hline & $\begin{array}{l}\text { Regular - quando alguns serviços podem ser acessados por } \\
\text { dispositivos móveis. }\end{array}$ & 2 \\
\hline & $\begin{array}{l}\text { Não existe - quando o portal náo oferece aplicativos para que o } \\
\text { usuário possa acessá-lo por meio de dispositivos móveis. }\end{array}$ & 0 \\
\hline \multirow{3}{*}{$\begin{array}{l}\text { Conformidade com normas } \\
\text { de acesso a portadores de } \\
\text { necessidades especiais }\end{array}$} & $\begin{array}{l}\text { Muito bom - (1) quando o portal oferece funcionalidades } \\
\text { para o acesso a portadores de necessidades especiais e ainda (2) } \\
\text { contém indicação de certificação de acessibilidade por órgão } \\
\text { competente. }\end{array}$ & 4 \\
\hline & $\begin{array}{l}\text { Regular - quando o portal apresenta pelo menos um dos itens } \\
\text { descritos acima. }\end{array}$ & 2 \\
\hline & $\begin{array}{l}\text { Não existe - quando o portal não oferece a opção para o acesso } \\
\text { a portadores de necessidades especiais. }\end{array}$ & 0 \\
\hline \multirow{2}{*}{ Alternativas outros idiomas } & $\begin{array}{l}\text { Localizado - quando o portal oferece a opção de escolher } \\
\text { outros idiomas para o usuário. }\end{array}$ & 4 \\
\hline & $\begin{array}{l}\text { Não localizado - quando o portal nấo oferece a opção de esco- } \\
\text { lher outros idiomas para o usuário. }\end{array}$ & 0 \\
\hline \multirow[t]{3}{*}{$\begin{array}{l}\text { Flexibilidade e eficiência do } \\
\text { portal }\end{array}$} & $\begin{array}{l}\text { Muito bom - (1) quando o site permite atingir o conteúdo } \\
\text { de interesse com um mínimo de cliques; (2) o site permite } \\
\text { fazer bookmark das páginas de interesse para consulta futura, } \\
\text { garante também a manutenção da referência ao longo do tem- } \\
\text { po; (3) as páginas do site podem ser impressas sem perda da } \\
\text { formataçấo. }\end{array}$ & 4 \\
\hline & Regular - quando o site oferece dois dos itens descritos acima. & 2 \\
\hline & $\begin{array}{l}\text { Não existe - quando o portal apresenta até um dos itens descri- } \\
\text { tos acima. }\end{array}$ & 0 \\
\hline
\end{tabular}




\begin{tabular}{|c|c|c|}
\hline Indicadores & Conceitos & Pontuação \\
\hline \multirow{3}{*}{$\begin{array}{l}\text { Instrumentos para o acompa- } \\
\text { nhamento das atualizaçóes }\end{array}$} & $\begin{array}{l}\text { Muito bom - quando o portal fornece mais de um instrumento } \\
\text { para que o usuário possa manter-se informado sobre as atuali- } \\
\text { zaçóes do site. }\end{array}$ & 4 \\
\hline & $\begin{array}{l}\text { Regular - quando o portal fornece um instrumento para que } \\
\text { o usuário possa manter-se informado sobre as atualizaçóes do } \\
\text { site. }\end{array}$ & 2 \\
\hline & $\begin{array}{l}\text { Não existe - quando o portal náo fornece instrumentos para } \\
\text { que o usuário possa manter-se informado sobre as atualizaçóes } \\
\text { do site. }\end{array}$ & 0 \\
\hline
\end{tabular}

Fonte: adaptado de Amorim (2012).

Hiperlinks

Tabela 3 - Hiperlinks

\begin{tabular}{|l|l|c|}
\hline Indicadores & Conceitos & Pontuação \\
\hline \multirow{5}{*}{$\begin{array}{l}\text { Link para organismos de } \\
\text { controle }\end{array}$} & $\begin{array}{l}\text { Muito bom - quando há link para (1) órgãos de controle nacio- } \\
\text { nais; (2) órgáos de controle internacionais, (3) órgáos de apoio } \\
\text { ao governo; (4) agencias reguladoras. }\end{array}$ & 4 \\
\cline { 2 - 3 } & Bom - quando o portal oferece três dos itens descritos acima. & 3 \\
\cline { 2 - 3 } & $\begin{array}{l}\text { Regular - quando o portal fornece pelo menos os itens 1 e 3 } \\
\text { descritos acima. }\end{array}$ & 2 \\
\cline { 2 - 3 } & Fraco - quando o portal fornece apenas o item um. & 1 \\
\cline { 2 - 3 } & $\begin{array}{l}\text { Não existe - quando não há link para órgãos de controle e de } \\
\text { apoio ao governo. }\end{array}$ & 0 \\
\hline \multirow{2}{*}{$\begin{array}{l}\text { Link para outros sites e por- } \\
\text { tais destinados a promover a } \\
\text { transparência }\end{array}$} & $\begin{array}{l}\text { Localizado - quando há link para outros sites e portais destina- } \\
\text { dos a promover a transparência. }\end{array}$ & $\begin{array}{c}\text { Não localizado - quando não há link para outros sites e portais } \\
\text { destinados a promover a transparência. }\end{array}$ \\
\hline
\end{tabular}

Fonte: adaptado de Amorim (2012).

\section{Transparência digital}

Esta dimensão tem por objetivo avaliar as informaçóes apresentadas pelo portal com a finalidade de fornecer ao usuário esclarecimentos e serviços sobre a estrutura e funcionamento do município, legislaçóes, modos e canais de participação no governo, programas e projetos realizados, em andamento e em discussão.

É subdividida em 4 categorias a saber: habilitação para a compreensão da informação, informaçôes financeiro-orçamentárias, informaçōes administrativas e instrumentos de acompanhamento e interação.

Habilitação para a compreensão da informação

Tabela 4 - Habilitação para a compreensão da informaçáo

\begin{tabular}{|l|l|c|}
\hline Indicadores & Conceitos & Pontuação \\
\hline \multirow{5}{*}{$\begin{array}{l}\text { Educação para o } \\
\text { controle social }\end{array}$} & $\begin{array}{l}\text { Muito bom - quando há informaçóes que apresentam, orientam e instruem o } \\
\text { usuário quanto ao uso do Portal da Transparência na forma de (1) manual, (2) } \\
\text { fale conosco, (3) tutorial, (4) perguntas frequentes, (5) cursos online sobre os } \\
\text { meios de controle social. }\end{array}$ & 4 \\
\cline { 2 - 3 } & Bom - quando o portal apresenta três dos itens descritos acima. & 3 \\
\cline { 2 - 3 } & Regular - quando o portal apresenta dois dos itens descritos acima. & 2 \\
\cline { 2 - 3 } & Fraco - quando o portal apresenta pelo menos um item descrito acima. & 1 \\
\cline { 2 - 3 } & Náo existe - quando não há nenhuma menção sobre o Portal da Transparência. & 0 \\
\hline
\end{tabular}




\begin{tabular}{|c|c|c|}
\hline Indicadores & Conceitos & Pontuação \\
\hline \multirow{3}{*}{$\begin{array}{l}\text { Informaçóes que } \\
\text { permitam ao ci- } \\
\text { dadáo identificar } \\
\text { os responsáveis } \\
\text { e autoridades e } \\
\text { entrar em contato }\end{array}$} & $\begin{array}{l}\text { Muito bom - quando há (1) lista com nomes, cargos e atribuiçóes das autorida- } \\
\text { des governamentais; (2) há indicaçấo do local de atendimento presencial e de } \\
\text { formas de contato por telefone, por meio eletrônicos ou plataformas web. }\end{array}$ & 4 \\
\hline & Regular - quando o portal apresenta pelo menos o item 2 descrito acima. & 2 \\
\hline & $\begin{array}{l}\text { Não existe - quando não há lista com nomes, cargos e atribuiçóes das autorida- } \\
\text { des governamentais; não há indicação do local de atendimento presencial e dos } \\
\text { meios de contato por telefone ou por meios eletrônicos. }\end{array}$ & 0 \\
\hline \multirow{3}{*}{$\begin{array}{l}\text { Conselhos } \\
\text { Nacionais }\end{array}$} & $\begin{array}{l}\text { Muito bom - quando há (1) informaçoes sobre a estrutura e o funcionamento dos } \\
\text { Conselhos Nacionais e, em especial, (2) sobre o conselho voltado para a transparência. }\end{array}$ & \\
\hline & Regular - quando há notícias sobre Conselhos Nacionais. & 2 \\
\hline & Não existe - quando não há indicação da existência de Conselhos Nacionais. & 0 \\
\hline \multirow[t]{5}{*}{ Ouvidoria } & $\begin{array}{l}\text { Muito bom - quando há (1) uma ouvidoria que acolhe as demandas para o } \\
\text { governo e ouvidorias específicas para atender a temas críticos (saúde, educação } \\
\text { etc.); (2) há informaçôes sobre a estrutura e o funcionamento da(s) ouvidoria(s); } \\
\text { (3) o serviço fornecido pela ouvidoria contempla, além de sugestôes, elogios e } \\
\text { reclamaçôes, acolhimento de denúncias dos atos de corrupçâo e exercício ne- } \\
\text { gligente ou abusivo de cargo, emprego ou funçāo na administraçáo pública; (4) } \\
\text { há informaçóes sobre o tratamento dado a demandas encaminhadas, meios de } \\
\text { acompanhamento dos processos. }\end{array}$ & 4 \\
\hline & Bom - quando o portal oferece três dos itens descritos acima. & 3 \\
\hline & Regular - quando o portal oferece dois dos itens descritos acima. & 2 \\
\hline & Fraco - quando o portal oferece pelo menos um item dos descritos acima. & 1 \\
\hline & Não existe - quando não há ouvidoria. & 0 \\
\hline \multirow{3}{*}{$\begin{array}{l}\text { Informaçōes } \\
\text { sobre os meios de } \\
\text { participaçáo }\end{array}$} & $\begin{array}{l}\text { Muito bom - (1) quando há informaçóes sobre o funcionamento e os meios de } \\
\text { participaçáo do cidadáo no governo; (2) quando há agenda com a programaçấo } \\
\text { dos meios de participaçấo. }\end{array}$ & 4 \\
\hline & Regular - quando o portal apresenta pelo menos um dos itens descritos acima. & 2 \\
\hline & $\begin{array}{l}\text { Não existe - quando não há informaçốes sobre o funcionamento e os meios de } \\
\text { participaçấo do cidadâo }\end{array}$ & 0 \\
\hline \multirow{5}{*}{$\begin{array}{l}\text { Funcionamento } \\
\text { do governo }\end{array}$} & $\begin{array}{l}\text { Muito bom - quando há informaçōes atualizadas periodicamente que visem a es- } \\
\text { clarecer sobre o funcionamento institucional do governo por meio de documentos e } \\
\text { aplicativos que expliquem como funciona a tramitaçáo de leis, decretos, orçamento, } \\
\text { bem como o período de encaminhamento de projetos de iniciativa popular etc. }\end{array}$ & 4 \\
\hline & $\begin{array}{l}\text { Bom - quando há informaçôes que visem a esclarecer sobre o funcionamento } \\
\text { institucional do governo por meio de documentos que esclareçam, pelo menos, } \\
\text { como funciona a tramitação de leis, decretos, orçamento, ou o período de } \\
\text { encaminhamento de projetos de iniciativa popular etc. }\end{array}$ & 3 \\
\hline & $\begin{array}{l}\text { Regular - quando as informaçōes que visem a esclarecer sobre o funcionamen- } \\
\text { to institucional do governo estáo desatualizadas. }\end{array}$ & 2 \\
\hline & Fraco - quando há informaçōes dispersas na seção de notícias. & 1 \\
\hline & $\begin{array}{l}\text { Não existe - quando não há informaçóes que visem a esclarecer sobre o funcio- } \\
\text { namento institucional do governo }\end{array}$ & 0 \\
\hline \multirow{5}{*}{$\begin{array}{l}\text { Legislaçôes do } \\
\text { governo }\end{array}$} & $\begin{array}{l}\text { Muito bom - (1) quando o governo publica, diária e sistematicamente, na forma de diá- } \\
\text { rio oficial eletrônico, atos administrativos, decretos e leis; (2) quando mantém os arqui- } \\
\text { vos da legislação do país há pelo menos cinco anos; (3) quando permite que os cidadãos } \\
\text { acompanhem as atualizaçôes da legislação por meios de mecanismos eletrônicos; (4) } \\
\text { quando é possível imprimir os arquivos, fazer download e encaminhar por e-mail. }\end{array}$ & 4 \\
\hline & Bom - quando o portal oferece três dos itens descritos acima. & 3 \\
\hline & Regular - quando o portal oferece dois dos itens descritos acima. & 2 \\
\hline & Fraco - quando o portal oferece pelo menos um dos itens descritos acima. & 1 \\
\hline & $\begin{array}{l}\text { Não existe - quando o governo não publica seus atos administrativos, decretos } \\
\text { e leis no portal. }\end{array}$ & 0 \\
\hline \multirow{3}{*}{$\begin{array}{l}\text { Programas e pro- } \\
\text { jetos do governo }\end{array}$} & $\begin{array}{l}\text { Muito bom - (1) quando há informaçóes atualizadas sistematicamente sobre } \\
\text { programas e projetos do país em andamento; (2) quando há meios de contato } \\
\text { para que o usuário possa obter mais informaçôes sobre programas e projetos. }\end{array}$ & 4 \\
\hline & Regular - quando o portal oferece pelo menos um dos itens descritos acima & 2 \\
\hline & $\begin{array}{l}\text { Não existe - quando não há informaçóes sobre programas e projetos do } \\
\text { país em andamento. }\end{array}$ & 0 \\
\hline
\end{tabular}

Fonte: adaptado de Amorim (2012). 


\section{Informaçôes financeiro-orçamentárias}

\section{Tabela 5 - Informaçóes financeiro-orçamentárias}

\begin{tabular}{|c|c|c|}
\hline Indicadores & Conceitos & Pontuação \\
\hline \multirow{3}{*}{$\begin{array}{l}\text { Declaração pré- } \\
\text {-orçamentária }\end{array}$} & $\begin{array}{l}\text { Muito bom - quando o governo publica (1) os pressupostos usados para desen- } \\
\text { volver o orçamento, tais como as receitas, despesas, e ( } 2 \text { ) níveis de dívida totais } \\
\text { previstos, e (3) alocaçóes indicativas entre setores do governo. }\end{array}$ & 4 \\
\hline & Regular - quando o governo publica os itens (1), (2) ou (3). & 2 \\
\hline & Não existe - quando o governo não publica a declaraçấo pré-orçamentária. & 0 \\
\hline \multirow{3}{*}{$\begin{array}{l}\text { Proposta do } \\
\text { Orçamento do } \\
\text { Executivo }\end{array}$} & $\begin{array}{l}\text { Muito bom - quando o governo apresenta os planos pormenorizados do governo } \\
\text { em termos de prioridades políticas e orçamentos para cada ministério e agência } \\
\text { para o próximo ano orçamentário. }\end{array}$ & 4 \\
\hline & $\begin{array}{l}\text { Regular - quando o governo apresenta os planos genéricos do governo em ter- } \\
\text { mos de prioridades políticas e orçamentos para cada ministério e agência para o } \\
\text { próximo ano orçamentário. }\end{array}$ & 2 \\
\hline & $\begin{array}{l}\text { Náo existe - quando o governo náo apresenta os planos do governo em termos } \\
\text { de prioridades políícas e orçamentos para cada ministério e agência para o } \\
\text { próximo ano orçamentário. }\end{array}$ & 0 \\
\hline \multirow{5}{*}{$\begin{array}{l}\text { Orçamento } \\
\text { Promulgado }\end{array}$} & $\begin{array}{l}\text { Muito bom - quando o governo publica o(s) documento(s) que autorizam o poder execu- } \\
\text { tivo a implementar as medidas políticas previstas no orçamento há pelo menos } 3 \text { anos. }\end{array}$ & 4 \\
\hline & Bom - quando o governo publica os itens (1); (2); (4) e (5) & 3 \\
\hline & Regular - quando o governo publica os itens (1); (4) e (5). & 2 \\
\hline & Fraco - quando o governo publica os itens (1) e (4). & 1 \\
\hline & Năo existe - quando o governo não publica relatórios de execuçấo e revisão fiscal. & 0 \\
\hline \multirow[t]{5}{*}{$\begin{array}{l}\text { Relatórios de } \\
\text { execuçâao e de } \\
\text { revisão }\end{array}$} & $\begin{array}{l}\text { Muito bom - quando o governo publica (1) informaçóes sobre receitas, as despe- } \\
\text { sas e a dívida incorrida através de publicaçóes periódicas; (2) quando apresenta } \\
\text { em Revisão Semestral, com resumo dos dados reais do orçamento dos primeiros } \\
\text { seis meses do ano (receitas, despesas e dívida) com reavaliação dos pressupostos } \\
\text { econômicos sobre os quais o orçamento foi inicialmente elaborado; (3) quando } \\
\text { apresenta ajustes orçamentários em razáo da reavaliaçáo para os próximos seis } \\
\text { meses; (4) quando o governo divulga relatório que mostra a situação das contas } \\
\text { do governo no final do exercício fiscal e inclui uma avaliaçáo do progresso feito } \\
\text { no alcance dos objetivos políticos enumerados no Orçamento Promulgado; (5) } \\
\text { quando o governo divulga relatório de instituiçáa suprema de auditoria que } \\
\text { avalia o desempenho financeiro do governo no exercício fiscal anterior. }\end{array}$ & 4 \\
\hline & Bom - quando o governo publica os itens (1); (2); (4) e (5) & 3 \\
\hline & Regular - quando o governo publica os itens (1); (4) e (5). & 2 \\
\hline & Fraco - quando o governo publica os itens (1) e (4). & 1 \\
\hline & Não existe - quando o governo não publica relatórios de execuçăo e revisão fiscal. & 0 \\
\hline \multirow[t]{3}{*}{$\begin{array}{l}\text { Abertura de da- } \\
\text { dos financeiro- } \\
\text {-orçamentários }\end{array}$} & $\begin{array}{l}\text { Muito bom - (1) quando há aplicativos que permitem acesso a dados e informa- } \\
\text { çōes financeiro-orçamentários do governo (abertura); (2) quando os arquivos } \\
\text { estấo disponíveis para download, quando as informaçôes estão disponíveis em } \\
\text { planilha eletrônica; (3) quando há aplicaçōes que permitem geraçấo de relató- } \\
\text { rios, quando é possível imprimir os arquivos ou encaminhar por e-mail. }\end{array}$ & 4 \\
\hline & Regular - quando o portal apresenta pelo menos o item um ou dois dos descritos acima. & 2 \\
\hline & Não existe - quando não há abertura de dados. & 0 \\
\hline \multirow[t]{5}{*}{$\begin{array}{l}\text { Orçamento } \\
\text { cidadáo }\end{array}$} & $\begin{array}{l}\text { Muito bom - quando o governo publica uma (1) versão simplificada dos docu- } \\
\text { mentos orçamentários; (2) quando utiliza emprego de linguagem não técnica e } \\
\text { formatos acessíveis de modo a facilitar a compreensão dos cidadãos e o seu enga- } \\
\text { jamento com os planos e açôes do governo durante o exercício fiscal; (3) quando } \\
\text { há informaçôes explicativas, didáticas e detalhadas (mediante textos, gráficos, } \\
\text { tabelas, infográficos, áudio e vídeo); (4) quando há aplicaçôes que permitem } \\
\text { geraçấo de relatórios. }\end{array}$ & 4 \\
\hline & Bom - quando o portal apresenta três dos itens descritos acima. & 3 \\
\hline & Regular - quando o portal apresenta dois dos itens descritos acima. & 2 \\
\hline & Fraco - quando o portal apresenta pelo menos um dos itens descritos acima. & 1 \\
\hline & Não existe - quando o governo não publica o Orçamento Cidadáo. & 0 \\
\hline
\end{tabular}

Fonte: adaptado de Amorim (2012). 


\section{Informaçóes administrativas (processos internos)}

Tabela 6 - Informaçóes administrativas

\begin{tabular}{|c|c|c|}
\hline Indicadores & Conceitos & Pontuação \\
\hline \multirow{5}{*}{$\begin{array}{l}\text { Folha de } \\
\text { pagamento }\end{array}$} & $\begin{array}{l}\text { Muito bom - quando há informaçóes detalhadas e atualizadas sistematicamente da } \\
\text { folha de pagamento dos (1) funcionários ativos e inativos da administraçáo direta; (2) } \\
\text { funcionários ativos e inativos da administração indireta do governo, (3) prestadores } \\
\text { de serviços; (4) quando há data da postagem, período de cobertura, fonte e indicação } \\
\text { do responsável pela prestação das informaçôes; (5) quando os arquivos estāo disponí- } \\
\text { veis para download, quando é possível imprimi-los ou encaminhá-los por e-mail. }\end{array}$ & 4 \\
\hline & Bom - quando o portal apresenta quatro dos itens descritos acima. & 3 \\
\hline & Regular -quando o portal apresenta três dos itens descritos acima. & 2 \\
\hline & Fraco - quando o portal apresenta dois dos itens descritos acima. & 1 \\
\hline & $\begin{array}{l}\text { Não existe - quando não há informaçóes gerais da folha de pagamentos dos } \\
\text { funcionários da administraçáo direta e da administração indireta do governo, } \\
\text { bem como dos prestadores de serviços. }\end{array}$ & 0 \\
\hline \multirow{5}{*}{ Licitaçóes } & $\begin{array}{l}\text { Muito bom - (1) quando há informaçôes atualizadas sistematicamente sobre } \\
\text { licitaçôes do governo, já realizadas e em andamento há pelo menos três anos; } \\
\text { (2) quando há documentos, formato em que são publicados com explicaçōes } \\
\text { detalhadas e didáticas (textos, gráficos, tabelas, infográficos, áudio e vídeo); (3) } \\
\text { quando há data da postagem, período de cobertura, fonte e indicação do respon- } \\
\text { sável pela prestação das informaçôes; (4) quando há meios de contato. }\end{array}$ & 4 \\
\hline & Bom - quando o portal não atende apenas ao item 2. & 3 \\
\hline & Regular - quando o portal apresenta dois dos itens descritos acima. & 2 \\
\hline & Fraco - quando o portal apresenta pelo menos um dos itens descritos acima. & 1 \\
\hline & $\begin{array}{l}\text { Não existe - quando não há informações atualizadas sistematicamente sobre } \\
\text { licitaçôes do governo. }\end{array}$ & 0 \\
\hline \multirow[t]{3}{*}{$\begin{array}{l}\text { Ações e decisões } \\
\text { governamentais }\end{array}$} & $\begin{array}{l}\text { Muito bom - (1) quando há informaçóes atualizadas sistematicamente sobre } \\
\text { decisōes governamentais em discussão; e existem documentos relativos ao fun- } \\
\text { cionamento administrativo do governo, como de audiências, eventos e reuniōes } \\
\text { com os ministérios; (2) quando os documentos contêm textos em diversos forma- } \\
\text { tos (textos - atas, relatórios - gráficos, imagens, vídeos etc.) }\end{array}$ & 4 \\
\hline & Regular - quando o portal apresenta pelo menos um dos itens descritos acima. & 2 \\
\hline & $\begin{array}{l}\text { Não existe - quando não há informaçôes noticiosas sobre decisōes e açôes gover- } \\
\text { namentais em discussão }\end{array}$ & 0 \\
\hline \multirow{5}{*}{$\begin{array}{l}\text { Abertura } \\
\text { de dados da } \\
\text { administração }\end{array}$} & $\begin{array}{l}\text { Muito bom - (1) quando há aplicativos que permitem o acesso a dados e infor- } \\
\text { maçôes administrativas do governo (abertura); (2) quando os arquivos estâo } \\
\text { disponíveis para download, quando as informaçôes estão disponíveis em plani- } \\
\text { lha eletrônica; (3) quando há aplicaçôes que permitem geração de relatórios; (4) } \\
\text { quando é possível imprimir os arquivos ou encaminhá-los por e-mail. }\end{array}$ & 4 \\
\hline & Bom - quando o portal apresenta três dos itens descritos acima. & 3 \\
\hline & Regular - quando o portal apresenta dois dos itens descritos acima. & 2 \\
\hline & Fraco - quando o portal apresenta pelo menos um dos itens descritos acima. & 1 \\
\hline & Não existe - quando não há abertura de dados. & 0 \\
\hline
\end{tabular}

Fonte: adaptado de Amorim (2012). 
Instrumentos de acompanhamento e interação

Tabela 7 - Instrumentos de acompanhamento e acessibilidade

\begin{tabular}{|c|c|c|}
\hline Indicadores & Conceitos & Pontuação \\
\hline \multirow{3}{*}{$\begin{array}{l}\text { Instrumentos para } \\
\text { o acompanhamen- } \\
\text { to das políticas } \\
\text { públicas }\end{array}$} & $\begin{array}{l}\text { Muito bom - quando há mecanismos que possibilitem ao cidadáo acompa- } \\
\text { nhamento das políticas públicas governamentais com informaçốes atualiza- } \\
\text { das sistematicamente (semestral), como relatórios e prestaçôes de contas. }\end{array}$ & 4 \\
\hline & $\begin{array}{l}\text { Regular - quando há mecanismos que possibilitem ao cidadão acompanha- } \\
\text { mento das políticas públicas governamentais, como relatórios e prestaçóes de } \\
\text { contas. }\end{array}$ & 2 \\
\hline & $\begin{array}{l}\text { Náo existe - quando náo há mecanismos que possibilitem ao cidadáo acom- } \\
\text { panhamento das políticas públicas governamentais, como relatórios e presta- } \\
\text { çôes de contas. }\end{array}$ & 0 \\
\hline \multirow[t]{2}{*}{ Agenda pública } & $\begin{array}{l}\text { Localizado - quando há publicação da agenda pública do chefe do poder } \\
\text { executivo }\end{array}$ & 4 \\
\hline & Não localizado - quando não há publicação. & 0 \\
\hline \multirow{3}{*}{$\begin{array}{l}\text { Avaliação dos ser- } \\
\text { viços do governo }\end{array}$} & $\begin{array}{l}\text { Muito bom - quando há meios de avaliaçáo dos serviços do governo com } \\
\text { publicação dos indicadores de satisfaçáo do usuário. }\end{array}$ & 4 \\
\hline & $\begin{array}{l}\text { Regular - quando há meios de avaliação dos serviços do governo sem publi- } \\
\text { cação dos indicadores de satisfaçấo do usuário. }\end{array}$ & 2 \\
\hline & Não existe - quando não há meios de avaliação dos serviços do governo. & 0 \\
\hline \multirow{2}{*}{$\begin{array}{l}\text { Acompanhamento } \\
\text { das demandas }\end{array}$} & $\begin{array}{l}\text { Localizado - quando há meios de acompanhamento das demandas do } \\
\text { cidadáo }\end{array}$ & 4 \\
\hline & $\begin{array}{l}\text { Não localizado - quando não há meios de acompanhamento das demandas } \\
\text { do cidadão. }\end{array}$ & 0 \\
\hline \multirow{2}{*}{$\begin{array}{l}\text { Respostas da } \\
\text { autoridade e } \\
\text { Perguntas e respos- } \\
\text { tas frequentes }\end{array}$} & $\begin{array}{l}\text { Localizado - quando há publicaçáo das respostas dadas por autoridades às } \\
\text { questôes apresentadas pelos cidadáos. }\end{array}$ & 4 \\
\hline & $\begin{array}{l}\text { Náo localizado - quando não há publicação das respostas dadas por autori- } \\
\text { dades às questōes apresentadas pelos cidadãos. }\end{array}$ & 0 \\
\hline \multirow{2}{*}{$\begin{array}{l}\text { Atendimento } \\
\text { online }\end{array}$} & Localizado - quando há meios de atendimento on-line. & 4 \\
\hline & Não localizado - quando não há meios de atendimento on-line. & 0 \\
\hline \multirow{2}{*}{ Debate prévio } & $\begin{array}{l}\text { Localizado - quando existem alternativas para debate prévio através de } \\
\text { plataformas deliberativas no website. }\end{array}$ & 4 \\
\hline & $\begin{array}{l}\text { Náo localizado - quando náo existem alternativas para debate prévio através } \\
\text { de plataformas deliberativas no website. }\end{array}$ & 0 \\
\hline \multirow{2}{*}{$\begin{array}{l}\text { Participação em } \\
\text { redes sociais }\end{array}$} & Localizado - quando há link para redes sociais da presidência no website. & 4 \\
\hline & $\begin{array}{l}\text { Não localizado - quando não há link para redes sociais da presidência no } \\
\text { website. }\end{array}$ & 0 \\
\hline
\end{tabular}

Fonte: adaptado de Amorim (2012).

No que se refere às duas dimensões, emerge da mensuração dois índices específicos e não necessariamente convergentes - um Índice de Eficácia Digital e um Índice de Transparência - que demonstram, isoladamente ou em seu conjunto, o nível de eficiência da e-transparência das iniciativas de transparência.

A partir do conjunto de resultados de cada dimensão, foi estruturado o conceito global da transparência digital do país analisado. Para a atribuição do conceito global, foi considerada a escala de pontuação apresentada na tabela 8 .

Tabela 8 - Intervalo percentual para a atribuição do conceito global

\begin{tabular}{|l|l|l|}
\hline Conceito global & Escala de pontuação & Escala percentual \\
\hline TA - transparência avançada & 4 a 3,2 & $100 \%$ a $80 \%$ \\
\hline TS - transparência significativa & 3,1 a 2,4 & $79,9 \%$ a $60 \%$ \\
\hline TM - transparência moderada & 2,3 a 1,6 & $59,9 \%$ a $40 \%$ \\
\hline
\end{tabular}




\begin{tabular}{|l|l|l|}
\hline Conceito global & Escala de pontuação & Escala percentual \\
\hline TF - transparência fraca & 1,5 a 0,8 & $39,9 \%$ a $20 \%$ \\
\hline TI - transparência insuficiente & Abaixo de 0,7 & Abaixo de $19,9 \%$ \\
\hline
\end{tabular}

Fonte: Amorim (2012).

\section{Teste do modelo proposto: aplicação no Portal do Poder Executivo Brasileiro}

Com a finalidade de testar o modelo proposto, optou-se avaliar o portal do Governo Federal do Brasil (www.brasil.gov.br). A escolha deste portal se deu pela familiaridade das pesquisadoras com o arcabouço legal que regulamenta a transparência pública e com o funcionamento da gestão das contas públicas do país. Além dessas razões, uma análise dessa natureza na língua nativa tornaria o processo menos complexo.

Tendo em vista a intenção de validar um modelo metodológico que seja capaz de avaliar portais nacionais dos executivos, destaca-se que os indicadores financeiro-orçamentários foram propostos com base nos padrôes de avaliação do International Budget Partnership (IBP). Este organismo realiza a Pesquisa de Orçamento Aberto por meio de oito documentos-chave do orçamento - (1) Declaração Pré-orçamentária; (2) Proposta de Orçamento do Executivo; (3) o Orçamento Promulgado; (4) Relatórios Durante o Ano; (5) Revisão Semestral; (6) Relatório de Fim de Ano; (7) Relatório de Auditoria; e (8) Orçamento do Cidadáo -, além de avaliar se os dados contidos nestes documentos são abrangentes e úteis.

A aplicação do modelo metodológico proposto ao portal do governo federal do Brasil foi realizada ao longo do dia 15/08/2014 e teve duração de 8h26m. Para minimizar ao máximo a subjetividade da avaliação, as pesquisadoras apreciaram cada indicador simultaneamente com o auxílio de ferramenta que permite comunicação por vídeo e áudio em tempo real. A nota de cada indicador foi atribuída pela construção do consenso e, se fosse o caso, ajustes nos parâmetros de análise.

A análise do portal do governo federal brasileiro obteve a pontuação 3,374. Com base na escala de pontuação apresentada na tabela 1 , isso significa que a e-transparência do portal brasileiro é de nível avançado.

\section{Considerações finais}

O presente trabalho teve como objetivo principal propor um modelo metodológico para a análise do estado da e-transparência em portais de executivos nacionais. Tal proposta consiste, principal e primeiramente, na criação e no teste de indicadores para a avaliação dos graus e níveis de transparência dos portais governamentais. Feito isto, propusemo-nos também, em um momento posterior, a aplicar o modelo metodológico aqui desenvolvido no portal do Poder Executivo brasileiro, a fim de testar sua eficácia e legitimar sua aplicabilidade em quaisquer portais voltados para experiências de transparência digital promovidas por governos. 
Entendemos que, para uma análise mais completa possível, que possibilitasse a mensuração da transparência nos portais, seria preciso que fossem avaliados tanto aspectos técnicos - atendendo as exigências para interfaces e plataformas digitais, haja vista que a avaliação da transparência é por meio digital quanto aqueles específicos da própria gestáo assim, para atender a esta demanda, optamos por dividir os aspectos necessários para a análise no que denominamos dimensóes, expostos na tabela 1.

É importante destacar que além de indicadores voltados para a avaliação de aspectos gerais e técnicos, estabelecemos como indicadores aqueles elementos que julgamos importantes e necessários para haver a transparência, ou seja, instrumentos imprescindíveis para a transparência da gestão, que denotam a eficiência do portal em dispor a informação de maneira clara e precisa ao cidadáo comum.

Ademais, é de suma importância ressaltar que o pesquisador que pretender utilizar o modelo proposto deve entender que é preciso considerar o dinamismo como um ingrediente no tratamento de alguns critérios, pois os portais não são iguais, tampouco as realidades dos países a serem analisados. É por esta razão que enfatizamos que os critérios não podem ser estáticos, engessados.

Em suma, embora acreditemos que conseguimos alcançar o objetivo proposto, qual seja, desenvolver com um modelo para a análise da transparência pública em portais governamentais, sugerimos que futuras pesquisas com a mesma finalidade se debrucem na avaliação da arquitetura do portal no que tange à localização da informaçáo, pois, ao longo do nosso trabalho verificamos que muitas vezes a informaçáo requerida está no portal, no entanto, o caminho para se chegar a ela é longo e não óbvio, o que dificulta sua localização. Do mesmo modo, notamos também que, em muitos casos, o excesso de informação pode dificultar a e-transparência, pois a localização daquilo que é do interesse do cidadão, em alguns casos, está disperso ou requer uma pesquisa avançada para que seja encontrada, o que torna árduo o processo de busca do cidadão.

\section{Referências bibliográficas}

AMORIM, P. K. Democracia e Internet: a transparência de gestão nos portais eletrônicos das capitais brasileiras. Tese (Doutorado em Comunicação Social) - Programa de Pós-Graduação em Comunicação e Cultura Contemporâneas, Universidade Federal da Bahia, Salvador, 2012.

AMORIM, P. K.; GOMES, W. O estado da transparência digital das capitais brasileiras: um estudo sobre e-transparência fiscal. In: Anais do V Congresso Anual da Associação Brasileira de Pesquisadores de Comunicaçáo e Política. Curitiba, Universidade Federal do Paraná, 2013. Disponível em: http://www.compolitica.org/home/wp-content/uploads/2013/05/GT04-\%C3\%94\%C3\%87\%C3\%B4-Internet-e-Pol+\%C2\%A1tica-PaulaKarini-Amorim.pdf. Acesso em 18 de maio de 2014.

BRAGA, S.S. Um estudo sobre a informatização dos órgáos legislativos na América do Sul. Opiniáo Pública, Campinas, v. 13, n. 1, p. 1-50, 2007.

DECLARAÇÃO DO GOVERNO ABERTO. Open Government 
Declaration. Disponível em: http://www.opengovpartnership.org/about/ open-government-declaration. Acesso em: 07 de janeiro de 2014

HOOD, C.; HEALD, D. (org). Transparency: the key to better governance?. Nova York: Oxford University Press, 2006.

MARGETTS, H. Transparency and digital government. In: HOOD, C.; HEALD, D. (org). Transparency: the key to better governance? p. 197210. Nova York: Oxford University Press, 2006.

MARQUES, F. P. J A. Internet e Transparência Politica. In: Anais do $23^{\circ}$ Encontro da Associação Nacional dos Programas de Pós-graduação em Comunicação. Belém do Pará, Universidade Federal do Pará, 2014. Disponível em: http://compos.org.br/encontro2014/anais/. Acesso em 10 de junho de 2014.

PESQUISA DO ORÇAMENTO ABERTO 2012. Relatório Open Budget Survey 2012. Disponível em: http://internationalbudget.org/wpcontent/uploads/OBI2012-Report-English.pdf. Acesso em 07 de janeiro de 2014.

PORTAL OPEN GOVERNMENT PARTNERSHIP. Open Government Partnership. Disponível em: http://www.opengovpartnership. org/countries Acesso em: 07 de janeiro de 2014.

SILVA, S. P. DA. Estado, democracia e internet: requisitos democráticos e dimensóes analíticas. Tese (Doutorado em Comunicação Social) - Programa de Pós-Graduação em Comunicação e Cultura Contemporâneas, Universidade Federal da Bahia, Salvador, 2009. 